\title{
The Incidence of Leprosy Between 1943 and 1973 in a Hyperendemic Area, Before and After the Introduction of Leprosy Control Measures
}

\author{
D. L. LEIKER* \\ Royal Tropical Institute, Amsterdam, The Netherlands \\ P. FISCHER \\ Leprosy Control Officer, Miei, Wandamen Bay, \\ Irian Jaya, Indonesia
}

A leprosy incidence study in a hyperendemic area (prevalence $7 \%$ ) is presented, based on whole population surveys at intervals, and covering a period of 30 years (1943-1973). The effect of three measures, introduced at different times, segregation of patients, mass chemotherapy and BCG vaccination, was assessed.

In the period 1943-1952 segregation of a proportion of the infectious patients was the only control measure. It was found that the incidence of leprosy remained nearly stable. Apparently this measure was virtually ineffective. In 1950 sulphone treatment was introduced. All segregated patients were treated. After 1952 an intensive casefinding, mass-treatment and caseholding programme was implemented. In the period 1958-1960 a very marked decline in the incidence was found. The incidence decreased by $74 \%$, as compared with the preceding 3-year period.

In 1957 a mass BCG vaccination campaign was carried out. The epidemiological data are not compatible with a spontaneous "natural decline". The decrease has to be ascribed to the control measures. If the mass treatment campaign alone was responsible for the decline in incidence one would expect a proportionally similar decline in the incidence of progressive forms of leprosy and of tuberculoid leprosy. It was found, however, that the decline in incidence of tuberculoid leprosy was much more marked and more sudden immediately following the BCG vaccination campaign. In 1958-1960 the incidence of $\mathrm{B}+\mathrm{L}$ cases had decreased by $41 \%$ as compared with the preceding 3 -year period, but the incidence of tuberculoid leprosy had decreased by $86 \%$.

It is concluded that the decline of progressive forms of leprosy and a proportionally similar decline of tuberculoid leprosy was due to the mass treatment campaign, but that the BCG vaccination campaign had contributed additionally and significantly to the decline of tuberculoid leprosy. It is encouraging to learn from this example that with conventional leprosy control measures, provided that they are conscientiously applied, rapid and impressive results can be obtained. The leprosy case load was reduced to such low proportions that general basic health services should be able to cope with the remaining case load.

\footnotetext{
* Dermatologist, former head of Leprosy Control Division, Department of Health, West New Guinea.

Received for publication 14 August, 1975.
} 


\section{Introduction}

Wandamen Bay is located in the south west corner of Geelvink Bay in Northern Irian Jaya, Indonesia. Between 1952 and 1957 an intensive study on leprosy was carried out by the first author. In 1972 and 1973 whole population surveys were repeated by the second author. Together, the data give a reliable picture of the course of leprosy in a row of villages during a period of 30 years. Since, in general, incidence studies on leprosy are scarce and incidence studies prior to and after the introduction of leprosy control activities are even more scarce, the results are published in some detail.

\section{Demographic Data}

The population of the east coast of Wandamen Bay is living in a row of villages shown in Fig. 1. The northern villages are located at the coast. A few villages in the south are located inland. The distance between the villages is, on the average, only a few kilometres. The main occupation is agriculture and fishing. The staple food is sagoe, cassave and sweet potatoes. The economical level is a subsistence economy.

The two northern villages, Wasior and Miei, differ slightly from the others. Wasior is the civil administration headquarters of the area. A number of civil servants from other parts of Irian Jaya are employed in the various departments. Miei is the headquarters of the Mission, the site of the only health centre and of the only secondary school in the area. (Recently a district hospital was built in Wasior.) The presence of a few Chinese shops makes these villages the main shopping and trading centre of the area, frequently visited by people from other villages. The third village in the row is the leprosarium, consisting of a row of houses on pilings at the beach, a small hospital, an occupational therapy building, a shop, a school and a church. Communication between the villages is via a single north-south track through the villages; or at low tide via the beach, or by sea.

A part of the population of Wandamen Bay is temporarily or semipermanently absent. The majority of the emigrants are living in the nearest town, Manokwari, or are employed by the oil company at Sorong (usually on a 1 year contract basis). These emigrants too were examined between 1952 and 1957. A large proportion returned to Wandamen Bay after 1962, and have been re-examined since.

\section{History of Leprosy}

The history of leprosy was studied in detail between 1952 and 1955 . Genealogical tables, comprising 5 generations, were compiled of all patients. The origins of the clans and the family relationship were studied.

Data were established by referring to events which were well known to everybody and at the same time are fixed by records, e.g. beginning and end of the war, arrival of the first civil administrator, opening of the first school.

All information on patients who had died prior to the survey was cross-checked with other informants, frequently with informants from other villages too. In 1952 a high proportion of the patients with onset of the disease after 1942 were still alive and were examined. However, a number of lepromatous and borderline 


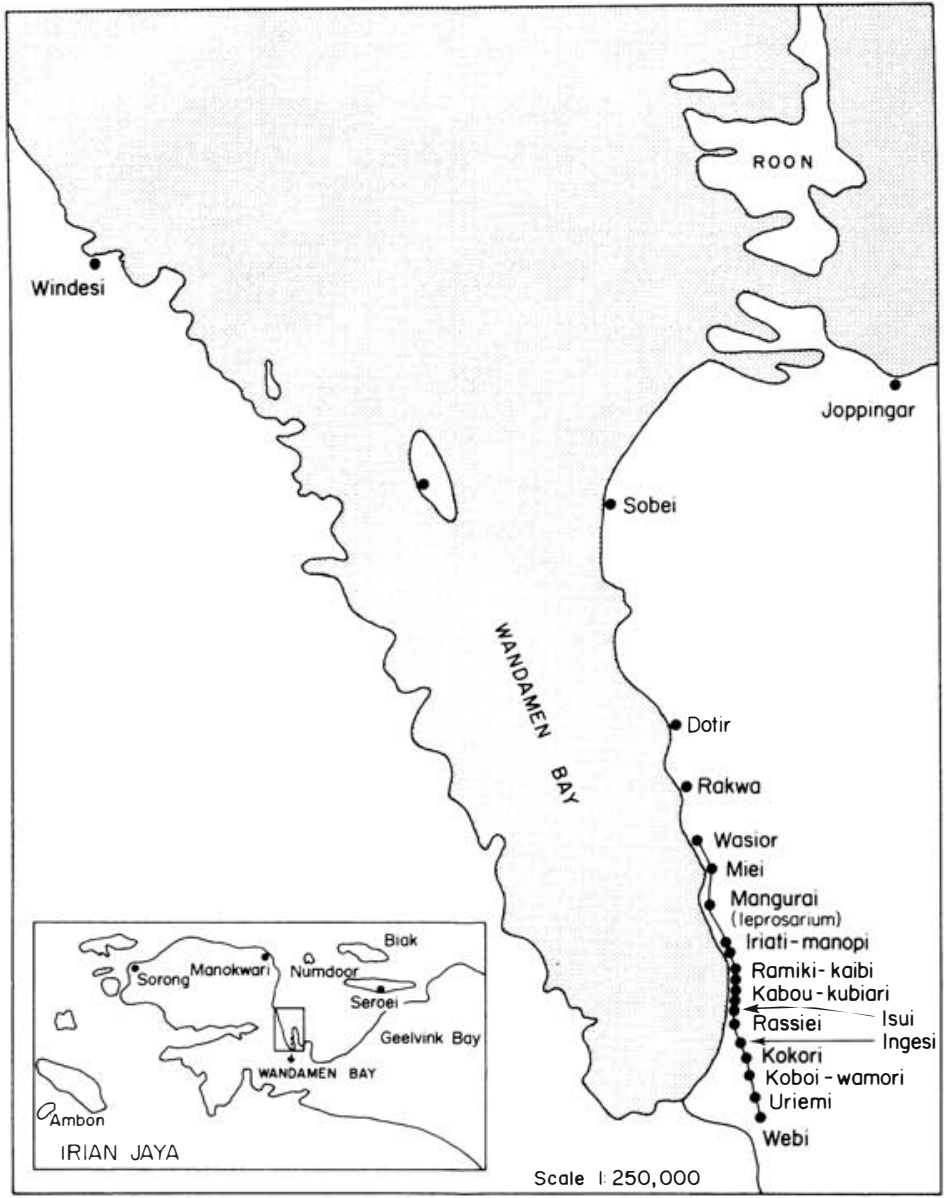

Fig. 1. Villages of Wandamen Bay, Indonesia.

patients had died, but with the exception of some early cases, their case histories could still be completed. No attempt was made to collect information on deceased tuberculoid and indeterminate patients, as such information would necessarily be too unreliable. The data presented in this report are regarded as nearly complete, with the exception of some under-registration of tuberculoid and indeterminate leprosy in the period between 1943 and 1952.

The first known patient in Wandamen Bay, a man in Miei, showed the first signs of the disease in 1904. Our informant, his son, confirmed that a few years earlier his father had visited Manokwari and had stayed for some months with immigrants from Numfor, living in Manokwari. The clan name of the first patient indicates that this clan originated from Numfor and this explains why he stayed with the Numfor immigrants at Manokwari. 
Leprosy was introduced in Manokwari around 1870 and was reported to be spreading markedly in 1879. Around 1900 the disease had become highly endemic in this area.

The second patient in Wandamen Bay, a man in Wasior and a relative of the mother of the first patient, was seen in 1907. This patient was living in a large clan-house (several closely related families living together in a large, turtleshaped house on pilings at the beach). The disease spread rapidly in this house. The first civil administrator, who arrived in 1906, induced the people to move from the large clan-houses to smaller family houses. Soon leprosy patients were found in many houses in the village.

In 1935 a visiting medical officer (Bierdrager, unpublished) found a leprosy prevalence rate of $16 \%$ in Wasior. The spread of leprosy to the other villages was relatively slow and irregular. In 1925, a married couple, both with leprosy, originating from Manokwari, introduced the disease in Manopi. In 1927 the first patient was seen in Kubiari in a house which was frequently visited by sagoe traders from Windesi (leprosy was introduced in Windesi between 1915 and 1920). A lepromatous patient from Windesi lived in this house for some time.

In 1928 a woman from Miei married in Wamori (Tandia) and developed lepromatous leprosy.

Around 1930 a man in Sirabi (Rassiei), who had lived in Wasior, developed leprosy.

In 1934 the first patient was seen in Ramiki-Kaibi, a relative of the first patient in Manopi.

In 1935 the first patient was seen in Isui, a member of a clan which came from Wasior.

In the same year the first patient was seen in Kabon, a woman originating from Kaibi.

Between 1930 and 1940 in most villages the disease was spreading rapidly to many other houses. An analysis of the genealogical tables, however, shows that the spread was not even. Frequently, no new cases were seen in neighbouring houses, while outbreaks of leprosy were recorded in more distant houses. A very high proportion of the new cases was seen in houses which were not marked by proximity to houses with sources of infection, but in other houses connected by family relationship with known patients and by intermarriage. Apparently the chance of infection in this area was markedly influenced by the degree of contact with the sources of infection. The social customs in this area limit significantly the degree of contact between nonrelatives. Even in 1952 when the first whole population survey was carried out it was found that, though leprosy was found to be highly endemic in all villages, the distribution of the cases was still uneven.

\section{Statistics}

The first whole population survey was carried out in 1952 by Sloan and Leiker.

In 1955 a house to house census and survey was carried out again, and 92\% of the population were examined. The remaining $8 \%$ were temporarily absent from the area. They were examined soon after return to the area in the following years. A leprosy prevalence rate of $7.7 \%$ was found, not including 
patients from outside the area, who had developed the first signs of leprosy prior to immigration to Wandamen Bay. It may be assumed that in 1957 virtually all patients were registered. In 1962 the medical officer left and casefinding and treatment were continued by a trained Papuan leprosy control officer. In 1973 a house to house census and survey was carried out again by the second author of this article. The fact that in this survey only a few unregistered patients were found confirmed the opinion that most new patients had been registered fairly soon after the onset of the first symptoms of the disease.

It is therefore believed that, with the exception of registration of a number of patients with mild selfhealing tuberculoid leprosy in the period between 1943 and 1952, virtually all patients in the period between 1943 and 1973 have been registered.

Though in the great majority of the patients the year of onset of the disease is regarded as fairly accurate, the possibility exists that in a proportion of the patients signs of the disease were already present before they were noticed. The data are therefore grouped in 3-year periods. Table 1 shows the average incidence of leprosy in 3-year periods between 1943 and 1973. A fairly stable pattern of leprosy in the first 15 years is followed by a dramatic decline in incidence in the next 3-year period, not followed by a marked further decline in the next 10 years, and a slight increase in the last few years of the period. Age at onset is given in Table 2, and sex and type indices are given in Table 3.

\section{Leprosy Control Activities}

Before 1942 groups of patients were segregated at a few sites outside the villages. However, they used to live together with other members of the family. In 1934 a few patients were sent to a leprosy colony at Seroei and a few were sent to the leprosarium at Ambon.

In 1949 the patients were largely concentrated in one village at the site of the present leprosarium. After 1950 the number of segregated patients increased gradually, but by 1955 a relatively high percentage of bacteriologically positive patients were actually living in the leprosy colony. Even then segregation was not strict. Relatives were visiting the patients regularly, not seldom staying in the colony and patients frequently visited the trading centres at Miei and Wasior or visited relatives in other villages.

The second leprosy control measure was the introduction of sulphone therapy in 1950, initially with diasone, followed in 1952 by DDS. In 1950 all patients in the leprosy colony and many patients in the northern villages were on treatment. From 1952 onwards most registered patients in other villages too were treated fairly regularly.

The third factor which may have influenced the incidence of leprosy is a BCG mass vaccination campaign carried out in 1957. More than $80 \%$ of all tuberculin negative people, children as well as adults, were vaccinated. The fourth factor which deserves consideration is a "natural change" in the pattern. It was found in other studies, carried out in New Guinea, that epidemics of leprosy may be followed by a rapid spontaneous decline in the incidence of the disease. 
TABLE 1

Incidence and type of leprosy in 3-year periods

\begin{tabular}{|c|c|c|c|c|c|c|c|c|c|c|c|}
\hline & $\mathrm{L}$ & $\mathrm{B}$ & $\mathrm{L}+\mathrm{B}$ & $\mathrm{T}$ & I & $\mathrm{T}+\mathrm{I}$ & Total & Population & \multicolumn{3}{|c|}{ Average annual } \\
\hline & & & & & & & & & Incidence & $\mathrm{L}+\mathrm{B}$ inciden & incidence $(\%)$ \\
\hline $1943-45$ & 11 & 2 & 13 & 19 & 2 & 21 & 34 & Est. 2200 & 0.52 & 0.20 & 0.32 \\
\hline $1946-48$ & 17 & 1 & 18 & 22 & 2 & 24 & 42 & 2300 & 0.61 & 0.26 & 0.35 \\
\hline $1949-51$ & 14 & 5 & 19 & 21 & 5 & 26 & 45 & 2400 & 0.63 & 0.26 & 0.36 \\
\hline $1952-54$ & 15 & 1 & 16 & 25 & 1 & 26 & 42 & $2500^{a}$ & 0.56 & 0.21 & 0.35 \\
\hline $1955-57$ & 8 & 5 & 13 & 43 & 5 & 48 & 61 & $2600^{a}$ & 0.78 & 0.17 & 0.62 \\
\hline $1958-60$ & 8 & 0 & 8 & 6 & 2 & 8 & 16 & 2700 & 0.20 & 0.10 & 0.10 \\
\hline $1961-63$ & 5 & 1 & 6 & 5 & 0 & 5 & 11 & 3000 & 0.12 & 0.07 & 0.06 \\
\hline $1964-66$ & 3 & 1 & 4 & 9 & 0 & 9 & 13 & 3300 & 0.13 & 0.04 & 0.09 \\
\hline $1967-69$ & 1 & 0 & 1 & 2 & 0 & 2 & 3 & 3400 & 0.03 & 0.01 & 0.02 \\
\hline $1970-72$ & 4 & 3 & 7 & 7 & 1 & 8 & 15 & $3600^{a}$ & 0.14 & 0.04 & 0.08 \\
\hline 1973 & 0 & 2 & 2 & 3 & 0 & 3 & 5 & 3600 & 0.14 & 0.02 & 0.03 \\
\hline
\end{tabular}

$a$ Census. 
TABLE 2

Age at onset (in 3-year periods)

(a)

\begin{tabular}{|c|c|c|c|c|c|c|c|c|c|c|}
\hline & $0-4$ & $5-9$ & $10-14$ & $15-19$ & $20-29$ & $30-39$ & $40-49$ & $50+$ & Total & Child index \\
\hline $1943-45$ & 0 & 6 & 3 & 3 & 8 & 11 & 3 & 0 & 34 & $26 \%$ \\
\hline $1946-48$ & 1 & 14 & 4 & 4 & 6 & 9 & 4 & 0 & 42 & $45 \%$ \\
\hline $1949-51$ & 4 & 8 & 3 & 2 & 11 & 9 & 8 & 0 & 45 & $33 \%$ \\
\hline $1952-54$ & 0 & 7 & 11 & 7 & 12 & 2 & 3 & 0 & 42 & $43 \%$ \\
\hline $1955-57$ & 3 & 13 & 9 & 8 & 10 & 10 & 6 & 2 & 61 & $41 \%$ \\
\hline $1958-60$ & 0 & 2 & 2 & 1 & 7 & 2 & 2 & 0 & 16 & $25 \%$ \\
\hline $1961-63$ & 0 & 0 & 0 & 2 & 1 & 4 & 4 & 0 & 11 & $0 \%$ \\
\hline $1964-66$ & 0 & 2 & 2 & 3 & 0 & 5 & 1 & 0 & 13 & $30 \%$ \\
\hline $1967-69$ & 0 & 1 & 0 & 0 & 0 & 1 & 1 & 0 & 3 & $33 \%$ \\
\hline $1970-72$ & 1 & 2 & 2 & 1 & 1 & 6 & 1 & 1 & 15 & $33 \%$ \\
\hline 1973 & & 1 & & 1 & 1 & & & 1 & 4 & $25 \%$ \\
\hline
\end{tabular}

\begin{tabular}{|c|c|c|c|c|c|c|c|c|c|c|}
\hline $943-57$ & $8(3.7 \%)$ & $48(22.3 \%)$ & $21(9.8 \%)$ & $24(11.2 \%)$ & $47(21.9 \%)$ & $41(19.1 \%)$ & $24(11.2 \%)$ & $2(0.9 \%)$ & 215 & $36 \%$ \\
\hline $1957-73$ & $1(2.6 \%)$ & $8(20.8 \%)$ & $6(15.6 \%)$ & $8(20.8 \%)$ & $10(16.1 \%)$ & $18(46.8 \%)$ & $9(23.4 \%)$ & $2(5.2 \%)$ & 62 & $24 \%$ \\
\hline $1958-63$ & $0(0 \%)$ & $2(7.4 \%)$ & $2(7.4 \%)$ & $3(11.1 \%)$ & $8(29.6 \%)$ & $6(22.2 \%)$ & $6(22.2 \%)$ & $0(0 \%)$ & 27 & $15 \%$ \\
\hline 1964-73 & $1(2.9 \%)$ & $6(17.1 \%)$ & $4(11.4 \%)$ & $5(14.3 \%)$ & $2(5.7 \%)$ & $12(34.3 \%)$ & $3(8.6 \%)$ & $2(5.7 \%)$ & 35 & $31 \%$ \\
\hline
\end{tabular}


TABLE 3

(a)

Sex and type in 3-year periods

\begin{tabular}{|c|c|c|c|c|c|c|c|c|c|c|}
\hline & \multicolumn{3}{|c|}{ Males } & \multicolumn{3}{|c|}{ Females } & \multirow{2}{*}{$\begin{array}{l}\text { Total } \\
m+f\end{array}$} & \multicolumn{3}{|c|}{ Sex index } \\
\hline & $L+B$ & $\mathrm{~T}+\mathrm{I}$ & Total & $L+B$ & $\mathrm{~T}+\mathrm{I}$ & Total & & all cases & $L+B$ & $T+I$ \\
\hline $1943-45$ & 10 & 9 & 19 & 3 & 12 & 15 & 34 & $56 \%$ & $77 \%$ & $43 \%$ \\
\hline $1946-48$ & 14 & 8 & 22 & 4 & 16 & 20 & 42 & $52 \%$ & $78 \%$ & $33 \%$ \\
\hline $1949-51$ & 10 & 12 & 22 & 10 & 13 & 23 & 45 & $49 \%$ & $50 \%$ & $48 \%$ \\
\hline $1952-54$ & 12 & 10 & 22 & 4 & 16 & 20 & 42 & $52 \%$ & $75 \%$ & $38 \%$ \\
\hline $1955-57$ & 7 & 18 & 25 & 6 & 30 & 36 & 61 & $41 \%$ & $54 \%$ & $38 \%$ \\
\hline $1958-60$ & 6 & 5 & 11 & 2 & 3 & 5 & 16 & $69 \%$ & $75 \%$ & $63 \%$ \\
\hline $1961-63$ & 5 & 3 & 8 & 1 & 2 & 3 & 11 & $73 \%$ & $83 \%$ & $80 \%$ \\
\hline $1964-66$ & 1 & 3 & 4 & 3 & 6 & 9 & 13 & $31 \%$ & $25 \%$ & $33 \%$ \\
\hline $1967-69$ & 0 & 2 & 2 & 1 & 0 & 1 & 3 & $67 \%$ & - & $66 \%$ \\
\hline $1970-72$ & 5 & 1 & 6 & 2 & 7 & 9 & 15 & $40 \%$ & $71 \%$ & $46 \%$ \\
\hline 1973 & 1 & 2 & 3 & 1 & 0 & 1 & 1 & $75 \%$ & $50 \%$ & $100 \%$ \\
\hline \multicolumn{11}{|l|}{ (b) } \\
\hline 1943-57 & 53 & 57 & 110 & 27 & 87 & 114 & 224 & $49 \%$ & $66 \%$ & $40 \%$ \\
\hline $1958-73$ & 18 & 16 & 34 & 10 & 18 & 28 & 62 & $55 \%$ & $64 \%$ & $47 \%$ \\
\hline
\end{tabular}




\section{Discussion}

The leprosy situation between 1943 and 1957 is best represented by the data of the period between 1955 and 1957 when surveys had been completed and all new cases were registered in an early stage of the disease.

If it is taken into account that in the previous years some tuberculoid patients had died and that in others with a mild selfhealing form of tuberculoid leprosy, e.g. a single superficial lesion, the diagnosis could no longer be confirmed during the surveys, the data show that the incidence of leprosy had been rather stable in these 15 years. The epidemiological pattern is not compatible with a recent epidemic of leprosy. Epidemics of leprosy are characterized by a very low type rate, a low child index, and a rather even distribution of cases in the community. Epidemics have exclusively been found in areas with a very low tuberculin index. Of 224 patients registered in the period 1943-1957, 65 were lepromatous, a type index of $29 \%$. Out of the 224 patients, in $86(38 \%)$ the disease started before the age of 15 . The disease was found to be markedly focalized into particular families in the community.

Tuberculosis is highly endemic in Wandamen Bay. In a tuberculin survey carried out in $1957,15 \%$ of the $0-9$ years old children, $51 \%$ of the age group 10-19 years, and 78\% of the adults showed a positive Mantoux reaction to 5-TU PPD. The sudden decline in incidence in the period between 1958 and 1960 therefore cannot be explained by a "natural decline" following an epidemic of leprosy. Segregation has been practised. In the period before 1952 only a fairly small proportion of the bacteriologically positive patients were to some extent segregated. In the period between 1952 and 1957 the number of segregated patients increased gradually, but only in the last few years a very high proportion of the bacteriologically positive patients were segregated soon after the diagnosis had been made. Even then segregation was far from strict. The segregation of patients does not seem to have had a significant effect on the incidence of the disease, which remained remarkably stable in the whole period between 1943 and 1957. Between 1950 and 1952 many bacteriologically positive patients and between 1952 and 1957 the great majority of the bacteriologically positive patients and a high proportion of the nonlepromatous patients were regularly treated with sulphones. In the period of 1955-1957 already a slight decline in the incidence of lepromatous and borderline patients was seen, followed in the next 3-year period by a marked decline in incidence.

If $4-5$ years is accepted as the average incubation period of leprosy, the time of decline corresponds with the elimination of sources of infection by chemotherapy. It is believed that the intensive casefinding, treatment and caseholding activities in the period between 1952 and 1957 are the most important factors responsible for the decline. However, in 1957 a very large proportion of the tuberculin negative population were vaccinated with BCG. Table 1 shows that in the period 1958-1960 the average annual incidence of lepromatous and borderline patients as compared with the following 3-year period decreased from $0.17 \%$ to $0.10 \%$, a decrease of $41 \%$, but that the incidence of tuberculoid and indeterminate leprosy decreased from $0.62 \%$ to $0.10 \%$, a decrease of $84 \%$.

The explanation cannot be that lepromatous leprosy is diagnosed on the average one or a few years later because of the less conspicuous symptoms in the early phase of the disease, because the figures do not change essentially if 
the next 3-year period too is taken into account. If treatment should be the only factor responsible for the decline of leprosy one would expect that the decline in e.g. the period 1958-1965 would be about the same in all types of the disease. The much greater decrease in incidence of tuberculoid leprosy as compared with lepromatous leprosy, immediately following the BCG vaccination campaign, therefore indicated that BCG vaccination contributed significantly to the decline of incidence of leprosy by preventing the development of tuberculoid leprosy.

The decline in prevalence continued slowly but steadily, in the period between 1963 and 1969. In the last 3-year period, however, the incidence of tuberculoid as well as lepromatous cases shows an increase again. Also, the average age of onset of the disease, which had shown a marked shift towards higher age groups in the period 1958-1963 as compared with previous years, shows a shift to the lower age groups again in the period 1964-1973, particularly in the last few years. This indicates that leprosy is not being kept under control. Part of the increase may be caused by the return of many emigrants to Wandamen Bay after the administration was taken over by Indonesia.

Among the immigrants were patients who were not on regular treatment when they arrived. Another cause may be that after the medical officer left in 1962 active casefinding and caseholding has diminished and the initiative for reporting for treatment has been left too much to the patients. The present study shows that an intensive casefinding, treatment and caseholding programme may result after about 5-7 years in a very marked decrease in the incidence of leprosy, and that BCG vaccination may contribute significantly to reducing the caseload of mild tuberculoid leprosy. The way towards eradication of the disease however is a very long one, requiring at least the maintenance of a very intensive approach for very long periods and most probably additional measures such as e.g. prophylactic treatment of a whole population or even more effective tools than at present are available.

Notwithstanding the conclusion that leprosy has not been finally controlled in this area, it is however encouraging to learn from this example that with the conventional methods, if conscientiously applied, in a short period of time impressive results can be achieved. The survey of 1973, including bacteriological examination of nontuberculoid patients, has shown that resistance to sulphones has not yet become a problem. No definite cases of sulphone resistance were found. Patients who had been discharged untimely or who had absconded from treatment and had relapsed, still responded to sulphone treatment. The explanation may be that a relatively high dosage of DDS, $600 \mathrm{mg}$ weekly, in most patients given in divided dosages, has been maintained and that the great majority of the bacteriologically positive patients have been treated very regularly. The prolonged success of the scheme after the medical officer had left must be ascribed to the activities of the single auxiliary worker, who carried on with the distribution of DDS and to the initiative of the population who, after a number of years of intensive health education and other control activities, had become very leprosy conscious and cooperative to the extent that most patients spontaneously reported for treatment soon after onset of the first symptoms. At present a few hospital beds only are sufficient for taking care of the complications of the disease. There is, in fact, no longer a need for a special leprosy centre. 
The caseload has been reduced sufficiently to enable complete integration of leprosy work into the general medical service. Since the basic general health service is still very weak, however, the objective of the leprosy activities should not be the eradication of the disease but the maintenance of a very low incidence of the disease and the available resources should be primarily used for strengthening the general basic health service.

\section{References}

Leiker, D.L. (1960). Epidemiological and immunological surveys in Netherlands New Guinea. Lepr. Rev. 31, 241.

Leiker, D. L. (1971). Some aspects of the epidemiology of leprosy. On the relationship of leprosy and other mycobacterial diseases. Int. J. Lepr. 39, 610.

Leiker, D. L. and Sloan, N. (1954). Leprosy in Netherlands New Guinea. Int. J. Lepr. 22, 431. 